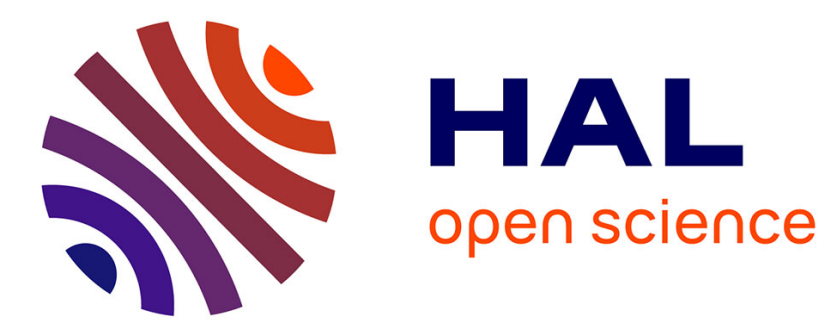

\title{
Indirect interband transition in hexagonal GaN
}

O Lancry, J.-L Farvacque, E Pichonat, Christophe Gaquière

\section{To cite this version:}

O Lancry, J.-L Farvacque, E Pichonat, Christophe Gaquière. Indirect interband transition in hexagonal GaN. Journal of Physics D: Applied Physics, 2011, 44 (7), pp.75105. 10.1088/00223727/44/7/075105 . hal-00594972

\section{HAL Id: hal-00594972 \\ https://hal.science/hal-00594972}

Submitted on 23 May 2011

HAL is a multi-disciplinary open access archive for the deposit and dissemination of scientific research documents, whether they are published or not. The documents may come from teaching and research institutions in France or abroad, or from public or private research centers.
L'archive ouverte pluridisciplinaire HAL, est destinée au dépôt et à la diffusion de documents scientifiques de niveau recherche, publiés ou non, émanant des établissements d'enseignement et de recherche français ou étrangers, des laboratoires publics ou privés. 


\title{
Indirect interband transition in hexagonal GaN
}

\author{
O. Lancry ${ }^{1}$, J.-L. Farvacque ${ }^{2}$, E. Pichonat ${ }^{1}$, C. Gaquière ${ }^{3}$ \\ ${ }^{1}$ Laboratoire de Spectrochimie Infrarouge et Raman (LASIR), UMR CNRS 8516, \\ Université des Sciences et Technologies de Lille, bât C5, 59655 Villeneuve d'Ascq \\ cedex, France. \\ ${ }^{2}$ Unité Matériaux et Transformations (UMET), UMR CNRS 8207, Université des \\ Sciences et Technologies de Lille, bât C6, 59655 Villeneuve d'Ascq cedex, France. \\ ${ }^{3}$ Institut d'Electronique de Microélectronique et de Nanotechnologie (IEMN), UMR \\ CNRS 8520, Cité Scientifique, Avenue Poincaré, BP 60069, 59652 Villeneuve d'Ascq \\ cedex, France.
}

E-mail : emmanuelle.pichonat@univ-lille1.fr

\begin{abstract}
In this paper, we report on optical investigations with Raman experiment to underline a new Ultra Violet (UV) luminescence band in hexagonal Gallium Nitride $(\mathrm{GaN})$ at $4.56 \mathrm{eV}$. GaN is a direct band gap semiconductor, the photoluminescence peak corresponding to the energy gap at $3.43 \mathrm{eV}$ dominates the spectrum. Nevertheless, other electronic interband transitions can appear on the spectrum: the electronic indirect interband transitions. We attribute one of them to the observed new photoluminescence band at $4.56 \mathrm{eV}$. This interpretation is supported by photoluminescence spectra obtained on three different samples at room temperature and at $50^{\circ} \mathrm{C}$ with UV excitation source: mbd-266 $\mathrm{nm}$ solid laser $(4.66 \mathrm{eV})$ and by the study of three criteria: the partly opposite parities of initial and final wave function, the implication of acoustic phonons and temperature control.
\end{abstract}

\section{Introduction}

Gallium Nitride and its alloys such as $\mathrm{Al}_{x} \mathrm{Ga}_{1-\mathrm{x}} \mathrm{N}$ (Aluminium Gallium Nitride) which remain direct gap for $\mathrm{x}$ up to $50 \%$ have been used for the fabrication of optoelectronic devices [1-2]. The interest of such materials results from the considerable improvements of growth techniques and advances in device applications. Consequently, there are many investigations of their basic physical properties. One of the most attractive properties is the direct character of such wide band gap materials (3.43 eV for $\mathrm{GaN}$ up to $4.53 \mathrm{eV}$ for $\mathrm{Al}_{\mathrm{x}} \mathrm{Ga}_{1-\mathrm{x}} \mathrm{N}$ with $\mathrm{x}=0.5$ ) [3-4] allowing the fabrication of $\mathrm{UV}$ detectors as well as blue lasers and electronic devices [5] with high mechanical and chemical stability. A useful technique to study the wide band gap is photoluminescence [6] where light emission energy gives information about crystalline quality, defects, donors, acceptors, temperature, stress, alloy composition ...In view to study the photoluminescence spectra of $\mathrm{GaN}$ and its alloys such as $\mathrm{Al}_{\mathrm{x}} \mathrm{Ga}_{1-}$. ${ }_{x} \mathrm{~N}$ up to $\mathrm{x}=0.5$, we used a very high energetic laser $(4.66 \mathrm{eV})$ as excitation source. This, fortunately, enabled us to observe a new emission line at $4.56 \mathrm{eV}$ in the $\mathrm{GaN}$ spectrum which we attribute to an indirect transition as will be shown afterward.

Then, we studied two different AlGaN samples grown on a GaN substrate with approximately the same x composition (13 and $15 \%$ ) but with different thicknesses (140 nm and $1 \mu \mathrm{m})$, in view to clarify the identification of the various luminescence peaks concerning such composite materials.

\section{Experimental setup}

The micro-photoluminescence measurements were performed at room temperature and at $50^{\circ} \mathrm{C}$ using a Horiba Jobin Yvon LabRam HR UV Micro-Raman system. Photoluminescence was excited by the mbd- $266 \mathrm{~nm}$ solid laser $(4.66 \mathrm{eV})$. The emission of the samples was then dispersed by a $800 \mathrm{~mm}$ focal length monochromator and detected with a backthinned illuminated CCD. A block diagram of the measurement system is drawn in figure 1. Spectral resolution after post mathematical treatment is $0.01 \mathrm{eV}$. The three different samples investigated in this paper are grown on sapphire 
substrates. The first one (sample A) is formed of only a non intentional doped (nid) $3 \mu \mathrm{m}$-thick GaN layer, the second one (sample B) is composed of an undoped $140 \mathrm{~nm}$-thick $\mathrm{Al}_{0.13} \mathrm{Ga}_{0.87} \mathrm{~N}$ layer $(13 \%$ aluminium content) grown on a nid GaN layer and the third one (sample C) of an undoped $1 \mu \mathrm{m}$-thick $\mathrm{Al}_{0.15} \mathrm{Ga}_{0.85} \mathrm{~N}$ layer (15\% aluminium content) grown on a nid $\mathrm{GaN}$ layer. The substrate do not have any effect on the characteristics of the UV luminescence band in hexagonal $\mathrm{GaN}$ at $4.56 \mathrm{eV}$.

\section{Results and discussion}

Figure 2 shows luminescence spectrum of sample A composed essentially of Gallium Nitride $(3 \mu \mathrm{m}$ thick) on which we can identify the luminescence band gap at $3.43 \mathrm{eV}$ [3] and another UV luminescence band at $4.56 \mathrm{eV}$. The latter is more energetic than the band gap transition, intensity and full width at half maximum (FWHM) of this band are lower than those of band gap luminescence, we attribute this band to a possible indirect interband transition. The very energetic laser, $4.66 \mathrm{eV}$, used to measure $\mathrm{Al}_{\mathrm{x}} \mathrm{Ga}_{1-\mathrm{x}} \mathrm{N}$ photoluminescence for $\mathrm{x}$ up to $50 \%$ allowed us to discover this indirect transition. The phenomenon can be explained as follows. The incident laser beam excites the electrons of the $\mathrm{GaN}$ valence band which after thermalization can populate the various minima present in the conduction band as long as the thermal energy (here the room temperature energy $0.025 \mathrm{eV}$ ) remains weaker than the energy barrier $\Delta \mathrm{E}$ surrounding these secondary minima (cf. figure 3 ). Thus, electrons recombine emitting mainly photons whose energy is equal to the energy gap but also a weaker proportion of photons whose energy is equal to a possible indirect interband transition energy.

Otherwise, if the condition $\Delta \mathrm{E}>\mathrm{kT}$ is not satisfied, excited electrons in the conduction band have enough thermal energy to thermalize at the conduction band minimum prior any direct recombination. In the $\mathrm{GaN}$ band diagram, the only possible indirect interband transition at $4.56 \mathrm{eV}$ is the one whose valence band minimum is located on the A point of the Brillouin zone (cf. figure 4).

Note that an indirect transition is possible as long as three criteria are satisfied:

1) The initial and final wave functions must have partly opposite parities. The parity of the conduction wave function at Point $\mathrm{A}$ and of the valence band at the $\Gamma$ point should be checked by ab initio calculations.

2) An indirect transition involves acoustic phonons in order to conserve crystal momentum. Thus, its intensity is generally very weak but should increase proportionally with kT. Such a temperature dependence should be checked experimentally.

3) However, the temperature must not be too important to avoid thermalization from the secondary minima towards the $\Gamma$ point minimum, which renders point 2 difficult to check experimentally. Table 1 displays temperature dependence of the $4.56 \mathrm{eV}$ peak intensity. Measurements were performed at room temperature and at $-50^{\circ} \mathrm{C}$, photoluminescence peak areas were compared. The measurement system does not allow to compare absolute intensities of spectra peaks, it's necessary to compare relative intensities. When $\mathrm{GaN}$ sample is cooled to $-50^{\circ} \mathrm{C}$, ratio between $3,43 \mathrm{eV}$-luminescence band gap area and 4,56 eV-luminescence band area decreases compared with the same ratio obtained at room temperature. These results confirm the criteria of temperature which must be not too high. This criteria is essential for electrons to remain in the secondary minima and recombine emitting photons whose energy is equal to $4.56 \mathrm{eV}$.

This finding enabled us to identify clearly the various luminescence peaks concerning AlGaN materials. Figure 5 and figure 6 show photoluminescence spectra of respectively sample B and sample C. The two samples are composed of $\mathrm{Al}_{\mathrm{x}} \mathrm{Ga}_{1-\mathrm{x}} \mathrm{N}$ layer grown on $\mathrm{GaN}$ with approximately the same $\mathrm{x}$ composition (respectively 13 and $15 \%$ ) but with different thicknesses (respectively $140 \mathrm{~nm}$ and 1 $\mu \mathrm{m})$. As the penetration depth of the UV laser $(266 \mathrm{~nm})$ in $\mathrm{Al}_{\mathrm{x}} \mathrm{Ga}_{1-\mathrm{x}} \mathrm{N}$ with $\mathrm{x} \approx 15 \%$ is around $60 \mathrm{~nm}$ [8-11], only $\mathrm{Al}_{\mathrm{x}} \mathrm{Ga}_{1-\mathrm{x}} \mathrm{N}$ layer is probed. When we supposed to obtain the same photoluminescence spectra for the two samples, we have in fact two different spectra. For sample $\mathrm{C}, \mathrm{Al}_{0.15} \mathrm{Ga}_{0.85} \mathrm{~N}$ layer luminescence band appears at $3.7 \mathrm{eV}$ (cf. figure 6). This value matches well with the calculated value of the $\mathrm{Al}_{0.13} \mathrm{Ga}_{0.87} \mathrm{~N}$ direct band gap denotated $\mathrm{E}_{\mathrm{g}}(\mathrm{x})$ obtained with the formula [4]: 


$$
\mathrm{E}_{\mathrm{g}}(\mathrm{x})=\mathrm{E}_{\mathrm{g}}^{\mathrm{GaN}}(1-\mathrm{x})+\mathrm{E}_{\mathrm{g}}^{\mathrm{AlN}} \mathrm{x}-\mathrm{bx}(1-\mathrm{x})
$$

with $x$ the aluminium content, $\mathrm{E}_{\mathrm{g}}^{\mathrm{GaN}}=3.43 \mathrm{eV}$ the Gallium Nitride direct band gap, $\mathrm{E}_{\mathrm{g}}^{\mathrm{AlN}}=6.2 \mathrm{eV}$ the Aluminium Nitride direct band gap and $b=1.3 \mathrm{eV}$ a non-linearity parameter. For sample $\mathrm{B}$, like in the previous spectrum, luminescence band gap of $\mathrm{Al}_{0.15} \mathrm{Ga}_{0.85} \mathrm{~N}$ is obtained at $3.7 \mathrm{eV}$. Furthermore, two other peaks are also identified: the first one, which is also the more intense, located at $3.4 \mathrm{eV}$, corresponds to the GaN direct band gap, the other one, clearly less intense and located at $4.56 \mathrm{eV}$, corresponds to the indirect interband transition described previously. Indeed, since the penetration depth is around $60 \mathrm{~nm}$ in $\mathrm{AlGaN}$, the UV beam intensity which reaches the GaN layer, after the 140 nm-thick AlGaN layer crossing, is given by Lambert's law in an absorbent material:

$$
\mathrm{I}=\mathrm{I}_{0} \mathrm{e}^{-\frac{140}{60}} \approx \frac{\mathrm{I}_{0}}{10}
$$

with $\mathrm{I}_{0}$ the incident beam intensity. This estimated value of the UV beam intensity which reaches the GaN layer is sufficient to obtain its photoluminescence spectrum.

The study of these three samples clarifies the identification of various luminescence peaks obtained with a very energetic laser.

\section{Conclusion}

Optical investigations by photoluminescence enabled us to observe a new luminescence UV emission at $4.56 \mathrm{eV}$ in hexagonal $\mathrm{GaN}$. This band is attributed to electronic indirect interband transition. This transition was discovered thanks to very energetic laser as excitation source used to characterize by photoluminescence the $\mathrm{Al}_{\mathrm{x}} \mathrm{Ga}_{1-\mathrm{x}} \mathrm{N}$ material with $\mathrm{x}$ up to $50 \%$. This interpretation is supported by photoluminescence spectra obtained on three different samples. Photoluminescence spectra of such composite materials are now easily treated, the identification of various luminescence peaks is now clearly demonstrated. This study is, to our knowledge, the only one which displays this indirect interband transition at $4.56 \mathrm{eV}$ in $\mathrm{GaN}$ material by photoluminescence experiments.

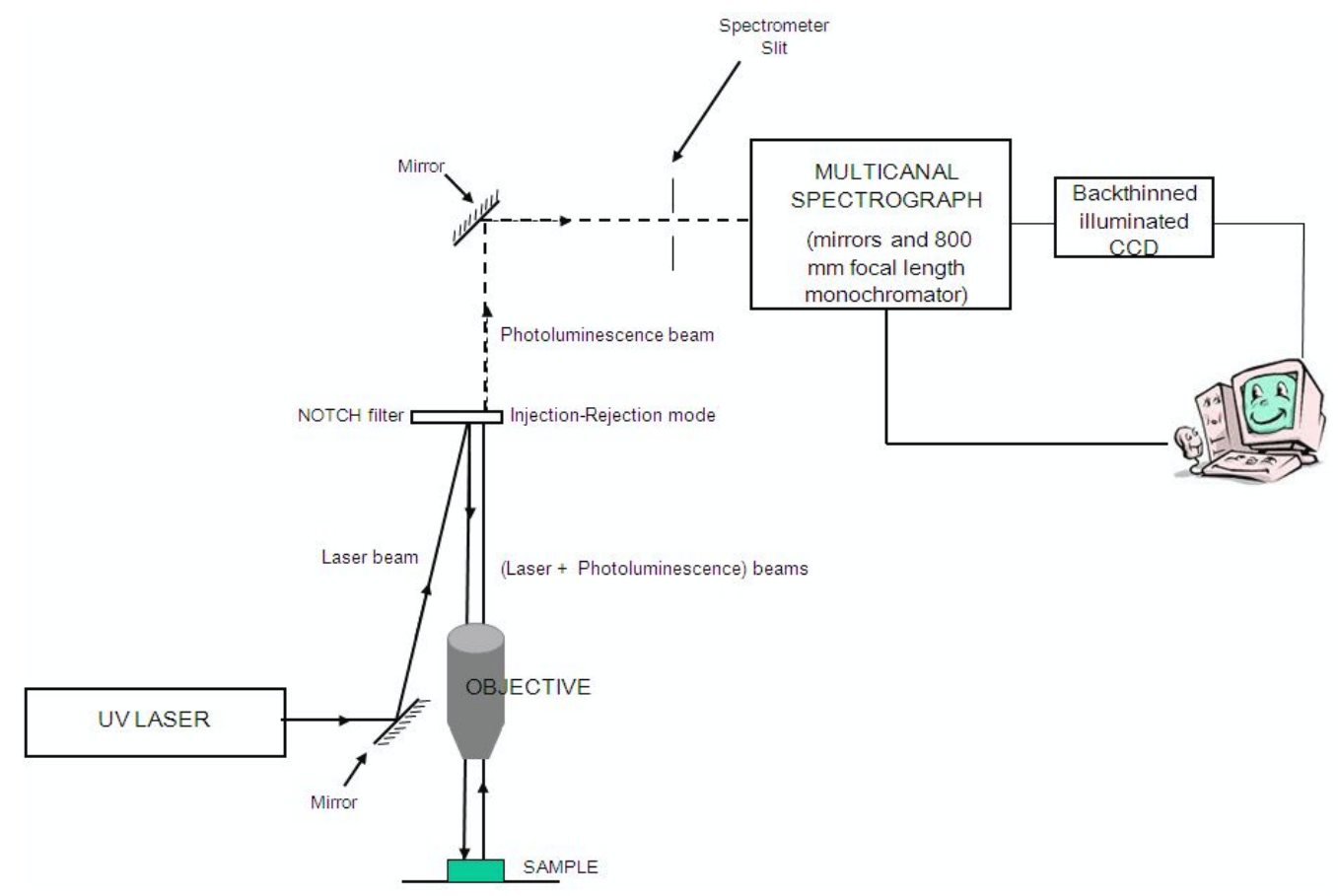

Figure 1. Block diagram of the measurement system. 


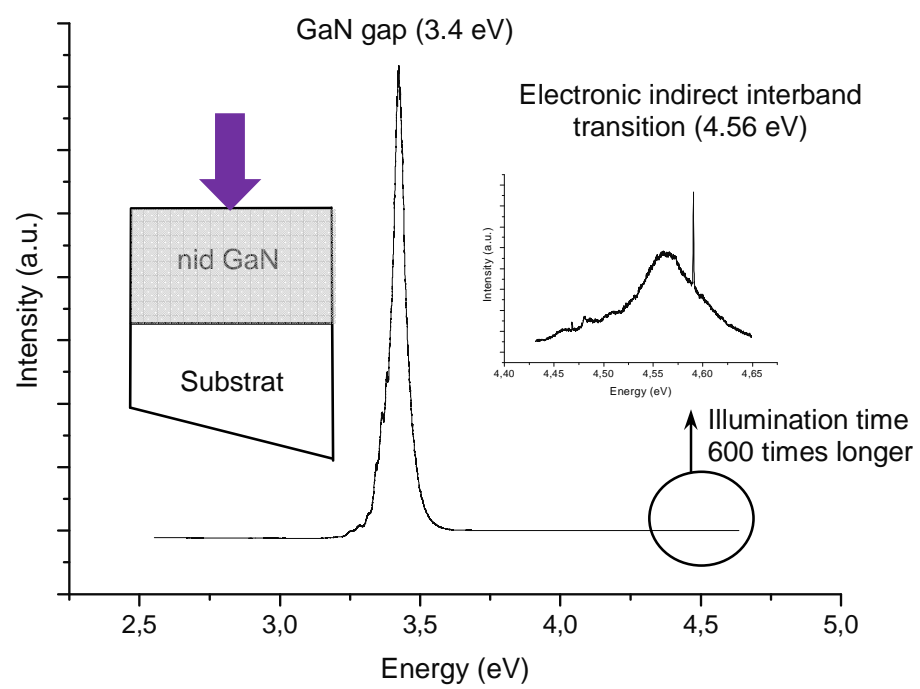

Figure 2. Sample A photoluminescence spectrum. To obtain a better spectral resolution between 4.4 $\mathrm{eV}$ and $4.7 \mathrm{eV}$, illumination time of the sample under UV light is 600 times longer than illumination time used to obtain the whole photoluminescence spectrum.

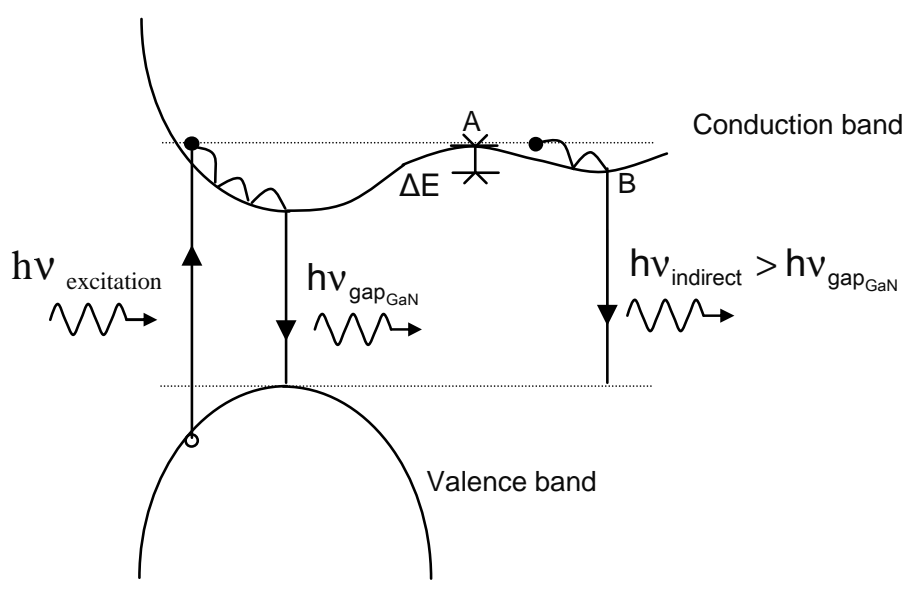

Figure 3. Electronic interband direct and indirect transitions of sample A. 


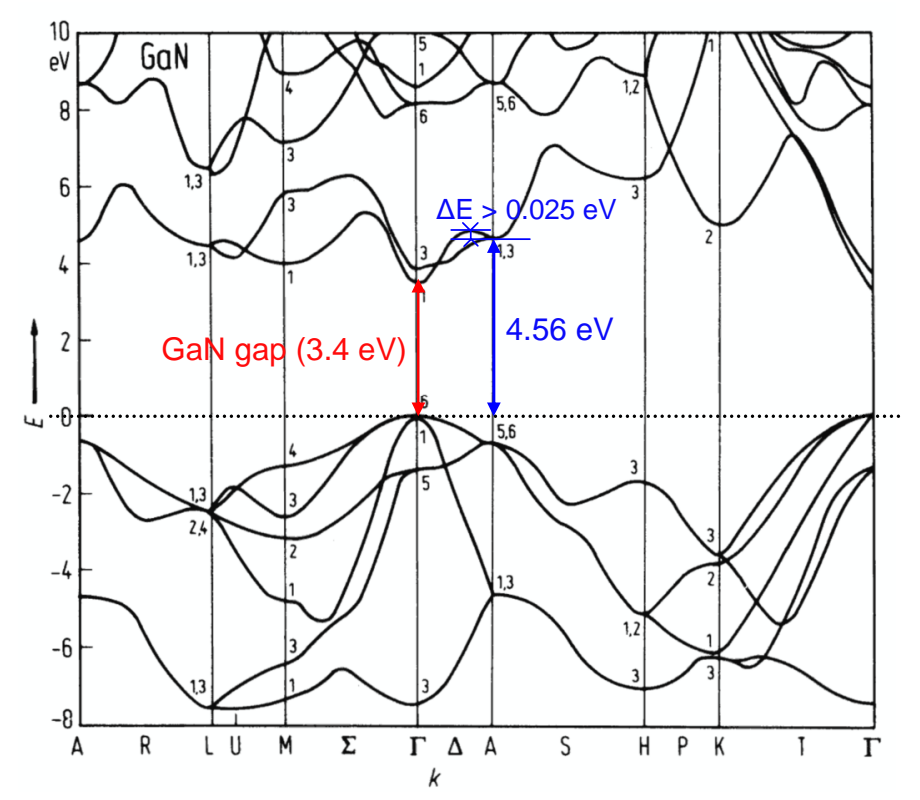

Figure 4. GaN band diagram [7].

\begin{tabular}{|l|c|c|c|c|c|c|}
\cline { 2 - 7 } \multicolumn{1}{c|}{} & \multicolumn{3}{c|}{ Room temperature } & \multicolumn{3}{c|}{$-50^{\circ} \mathrm{C}$} \\
\cline { 2 - 7 } & $\begin{array}{c}3,43 \mathrm{eV} \\
\text { peak area }\end{array}$ & $\begin{array}{c}4,56 \mathrm{eV} \\
\text { peak area }\end{array}$ & ratio & $\begin{array}{c}3,43 \mathrm{eV} \\
\text { peak area }\end{array}$ & $\begin{array}{c}4,56 \mathrm{eV} \\
\text { peak area }\end{array}$ & ratio \\
\hline Sample A & $6,28.10^{7}$ & $1,11.10^{6}$ & 56,6 & $2,25.10^{7}$ & $0,445.10^{6}$ & 50,6 \\
\hline Sample B & $1,24.10^{7}$ & $0,931.10^{6}$ & 13,3 & $3,04.10^{7}$ & $2,47.10^{6}$ & 12,3 \\
\hline Sample C & - & No peak & - & - & No peak & - \\
\hline
\end{tabular}

Table 1. Temperature dependence of the $4.56 \mathrm{eV}$ peak intensity observed in photoluminescence spectra of the three samples obtained at $-50^{\circ} \mathrm{C}$ and at room temperature. 


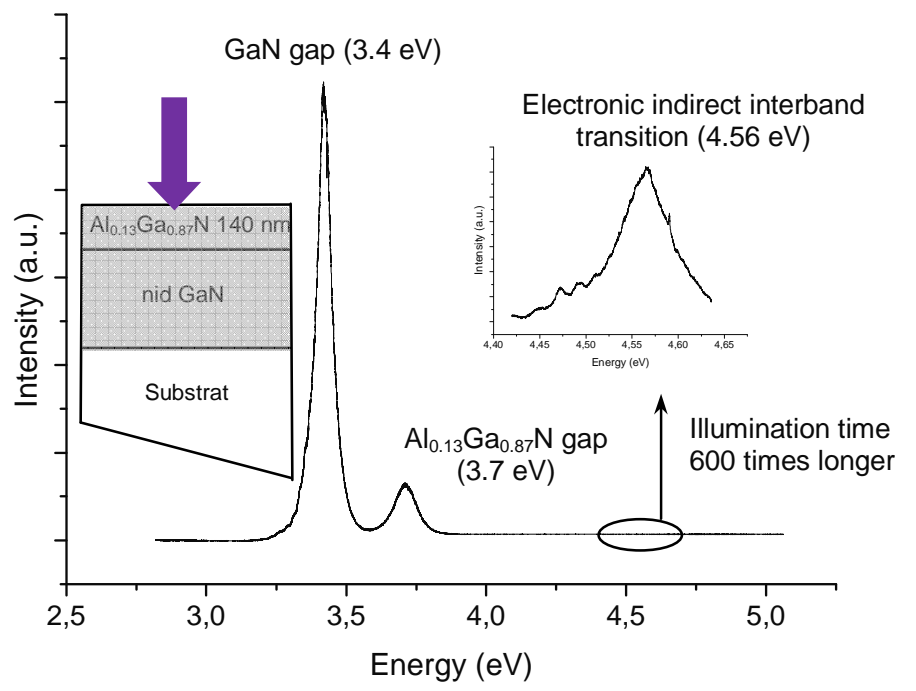

Figure 5. Sample B photoluminescence spectrum. To obtain a better spectral resolution between 4.4 $\mathrm{eV}$ and $4.7 \mathrm{eV}$, illumination time of the sample under UV light is 600 times longer than illumination time used to obtain the whole photoluminescence spectrum.

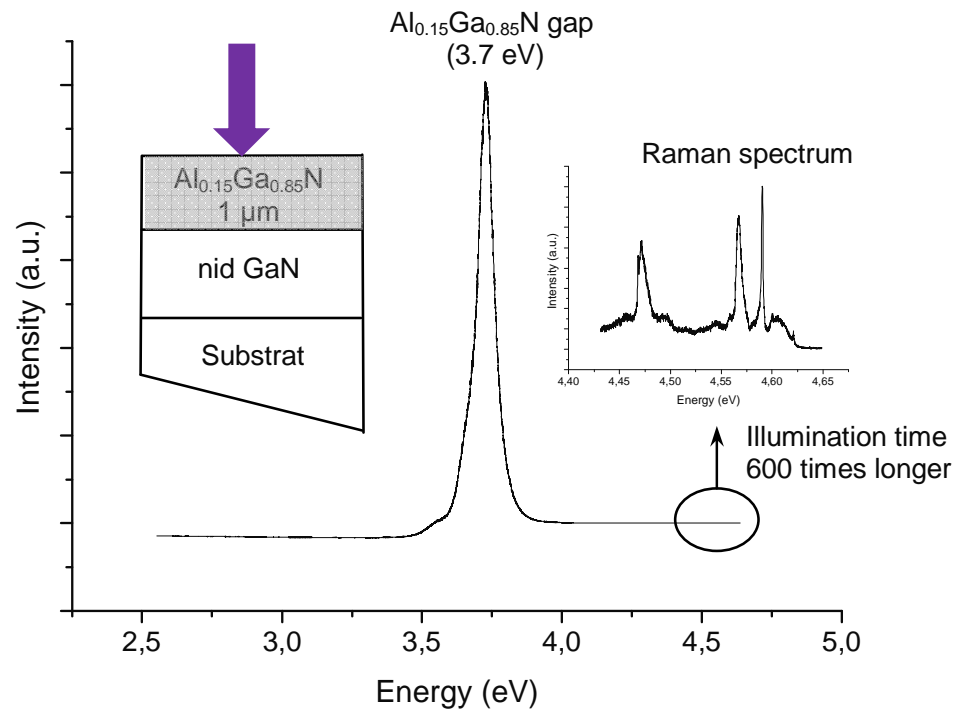

Figure 6. Sample $C$ photoluminescence spectrum.

To obtain a better spectral resolution between 4.4 $\mathrm{eV}$ and $4.7 \mathrm{eV}$, illumination time of the sample under UV light is 600 times longer than illumination time used to obtain the whole photoluminescence spectrum. 


\section{References}

[1] Lim B. W., Chen Q. C., Yang J. Y. and Khan M. A. 1996 High responsitivity intrinsic photoconductors based on $\mathrm{Al}_{\mathrm{x}} \mathrm{Ga}_{1-\mathrm{x}} \mathrm{N}$ Appl. Phys. Lett. 683761

[2] Nakamura S., Senoh M., Nagahama S., Iwasa N., Yamada T., Matsushita T., Sugimoto Y. and H. Kiyoku 1997 Room-temperature continuous-wave operation of InGaN multi-quantum-well structure laser diodes with a lifetime of 27 hours Appl. Phys. Lett. 701417

[3] Vurgaftman I. and Meyer J. R. 2003 Band parameters for nitrogen-containing semiconductors J. Appl. Phys. 943675

[4] Brunner D., Angerer H., Bustarret E., Freudenberg F., Hopler R., Dimitrov R., Ambacher O. and Stutzmann M. 1997 Optical constants of epitaxial AlGaN films and their temperature dependence J. Appl. Phys. 825090

[5] Duccatteau D., Minko A., Hoel V., Morvan E., Delos E., Grimbert B., Lahreche H., Bove P., Gaquière C., De Jaeger J. C. and Delage S. 2006 Output power density of 5.1/mm at $18 \mathrm{GHz}$ with an AlGaN/GaN HEMT on Si substrate IEEE Elec. Dev. Lett. 277

[6] Shigekawa N., Omodera K. and Shiojima K. 2002 Device temperature measurement of highly biased AlGaN/GaN High-Electron-Mobility Transistors Jpn. J. Appl. Phys. 461535

[7] Web site : http://www.ioffe.rssi.ru/SVA/NSM/Semicond/GaN/index.html, NSM-Archive, "GaN - Gallium Nitride"

[8] Perkowitz S. 1993 Optical characterization of semiconductors (London: Academic press)

[9] Muth J. F., Lee J. H., Shmagin I. K., Kolbas R. M., Casey J. H. C., Keller B. P., Mishra U. K. and Denbaars S. P. 1997 Absorption coefficient, energy gap, exciton binding energy, and recombination lifetime of $\mathrm{GaN}$ obtained from transmission measurements Appl. Phys. Lett. 71 2572

[10] Muth J. F., Brown J. D., Johnson M. A. L., Yu Z., Kolbas R. M., Cook J. W. and Schetzina J. F. 1999 Absorption coefficient and refractive index of GaN, AlN and AlGaN alloys GaN and related alloys; Proceedings of the Symposium (Boston, 30 nov.-4 dec. 1998)

[11] Demiryont H., Thompson L. R. and Collins G. J. 1986 Optical properties of aluminium oxynitrides deposited by laser-assisted CVD Appl. Opt. 251311

\section{Aknowledgements}

We aknowledge Myriam Moreau involved in photoluminescence measurements. 